\title{
COMPARATIVE STUDY ON THE MECHANICAL PROPERTIES AND ULTRASTRUCTURAL EGGSHELL TRAITS FOR DUMYATI AND MUSCOVY DUCKS
}

\author{
A.M.H. Ahmed \\ Department of Poultry Production, Faculty of Agriculture, University of Ain \\ Shams, Cairo, Egypt
}

\section{SUMMARY}

Egg quality, mechanical properties and Ultrastructural eggshell traits of Dumyati and Muscovy ducks were evaluated at beginning of laying period. A total of 100 fresh eggs were collected from 24 week-old Dumyati and Muscovy ducks fed a standard ration and reared under conventional management conditions. It was shown that average egg weight, egg width and egg shape index were higher in Muscovy eggs compared to Dumyati ones. Muscovy ducks produced significantly greater shell area when compared to Dumyati breed. The Muscovy eggs were significantly higher albumen height and quantity when compared to Dumyati eggs. With respect to breaking strength, it could be noticed that the breaking strength of Muscovy eggs were also significantly higher when compared to Dumyati breed. In accordance to eggshell ultrastructural, the present result showed that the Muscovy breed produced eggs with highly density mammillary pointed caps with irregular shape. Inversely, the Dumyati breed had low density rounded and conformity mammillary caps eggshells. Respecting confluence trait, data showed that the Muscovy eggs owned shells with higher values of confluence. With respect to alignment trait, the presented results showed that alignment comes out to be significantly differed between Muscovy and Dumyati breeds, where Dumyati eggs had the higher alignment value than Muscovy ones. Significant differences were found between Dumyati and Muscovy duck eggshells as for type B's structure. In conclusion, this study demonstrates the superiority for egg quality, mechanical properties and Ultrastructural eggshell traits of eggs from Muscovy ducks at beginning of laying period than Dumyati eggs.

Keywords: Duck breeds, egg quality, eggshell mechanical properties, ultrastructure

\section{INTRODUCTION}

Egg quality is the more important price contributing factor in table and hatching eggs. In several countries of the Far East duck eggs are produced and consumed in large quantities by the local population thus substituting hen eggs. In Egypt, duck eggs are mainly used for hatching fertile eggs and reproduction to produce ducks (meat production). Approximately $7-8 \%$ of the total amount of the eggs is broken throughout the transfer of the eggs from the breeders to the consumers. So, especially the amount of cracked and broken eggs results in a serious economical problem both for the breeders and the dealers (Hamilton, 1982). The eggshell is a bioceramic material in which the mineral ( $\mathrm{CaCO} 3$ in the polymorphic form of calcite) is intimately associated with an organic matrix (Nys et al., 2004). The mineral part

Issued by The Egyptian Society of Animal Production 
comprises spherulitic (mammillary cores) anchored on to the shell membranes and columnar crystal layers (palisades). The arrangement and size of crystals change across these layers (Rodriguez-Navarro et al., 2002). It is well established that the amount of mineral (eggshell thickness) is the main variable contributing to the mechanical properties of the shell. However, there is also evidence showing that the fabric or shell microstructure (defined as the size of the calcite crystals, their shape and crystallographic orientation) may also influence shell mechanical properties (Rodriguez-Navarro et al., 2002; Ahmed et al., 2005).

Moreover, some of the egg quality traits have significant and direct effects on the prices of especially commercial flocks. In the egg processing enterprises, the weight of eggshell, albumen and the yolk that form the egg as well as their rates affect the amount and price of the product (Altan et al., 1998). During the investigations made on the quality traits of the egg, the researchers had focused on the studies related to the increasing of the stiffness of the eggshell, because the quality of the eggshell has a vital importance for the laying force, embryo growth and the chick quality. Egg weight was easily predictable from egg length and width as positive association among these traits existed (Farooq et al., 2001). Information on egg weight along with egg width and length will further open the domain for trying out various prediction equations in order to predict eggshell weight and shell thickness (Khurshid et al., 2003).

Thus, the aim of this study is to give some insight into the mechanical and ultrastructural eggshell of the two breeds of ducks present in Egypt.

\section{MATERIALS AND METHODS}

One hundred eggs were collected from Muscovy and Dumyati ducks (50 eggs of each) reared in Elserow Duck Researches Station, Animal and Poultry Research Institute, Dumyat governorate, Egypt. Ducks were fed ad libitum with laying duck diet recommended by Animal and Poultry Researches Institute. The evaluations of egg quality were conducted at 24 weeks of duck age. Egg dimensions (length and width, mm) were measured with the electronic caliper. Shell weight was measured after washing the shells and drying overnight and the percentage of shell was calculated as:

Shell $\%=($ shell weight/egg weight $) \times 100$

Shell index $\left(\mathrm{g} / 100 \mathrm{~cm}^{2}\right.$, Sauveur, 1988) was calculated as

$\mathrm{I}=(\mathrm{W} / \mathrm{S}) \mathrm{X} 100$

The width to length ratio was shown in percentage points and constituted the egg shape index. The equation of Paganelli et al. (1974) was used to calculate the eggshell area (surface $\mathrm{cm}^{2}$ ): $\mathrm{S}=4.835 \mathrm{x} \mathrm{W}^{0.662}$, where $\mathrm{W}=$ egg weight. Eggshell thickness was measured $(\mathrm{mm})$ with the micrometer after breaking eggs. The breaking strength was measured according to Fathi and El-Sahar (1996) which assessed the resistance of the egg to crushing.

The height of thick albumen $(\mathrm{H})$ and the egg weight $(\mathrm{W})$ were used to calculate Haugh units from the formula of Williams (1992): $\mathrm{HU}=100 \log (\mathrm{H}+7.7-1.7$ $\mathrm{W}^{0.37}$ ), where $\mathrm{H}=$ thick albumen height, $\mathrm{W}=$ egg weight. Yolk diameter along the chalazae line was determined with the caliper $(\mathrm{mm})$. The ratio of the yolk height to its diameter in percentage points constituted the yolk index. 
The albumen weight was calculated from the difference between the entire egg weight and the yolk and eggshell weight. The contents of yolk, albumen and the eggshell by percentage were compared with the weight of a fresh egg.

\section{Preparation of samples for electron microscopy scanning}

At 24 weeks of age, eight samples of eggshell were randomly taken from each breed (Muscovy and Dumyati) to investigate ultrastructural variations. The specimens were prepared by cutting a piece $\left(1 \mathrm{~cm}^{2}\right)$ using a razor blade of shell from the equatorial region of each egg. Eggshell membranes were gently peeled from the edge of the sample inwards. To remove the remaining tightly bound membrane fibres, each sample was then immersed overnight in $6 \%$ sodium hypochlorite, $4.12 \%$ sodium chloride and $0.15 \%$ sodium hydroxide over day and night. Then, shell rinsed with distilled water and dried completely at room temperature until constant weight. Aluminium stubs were labelled and placed in stub boxes. Random sections of the shells were secured to a specimen stub. Treated shells were very brittle and required careful handling. The substances used to secure the specimens were tacky wax, Bond 527 glue (Bond Adhesive Company), double-sided stick tape, and Duco cement. A microwavable soy based wax was also used, but discontinued because the shells popped off of the wax. Specimens used for cross sections studies were secured using Duco cement: metal stub placed in cork holder, a dime-sized portion of glue was placed on a glass slide, and the top of the stub was lowered into the glue and rotated, leaving a thick and even layer on the surface. After the smooth layer of glue was obtained it was permitted to set up for 15 seconds. Eggshell specimens were placed in the cement as the cement began to cure. Once representative two specimens from examined eggs were secured to the stub and fixed on two sittings. The first, on the horizontal pose where the inner surface of the shell was upward of the stub (not in contact with it) this posture clear the various structures of the mammillary layer increase or reduce shell solidity. Second stance, vertically to measure total calcium columns, palisade and cap lengths (cross sectional). The stubs prepared to scan were placed in the sputter coater with a gold and palladium target. Shell specimens coated for $4 \frac{1}{2}$ minutes displayed charging problems when examined in JEOL JSM-T330A Microscope (SEM) at $15 \mathrm{Kv}$. Two-step coating was used on samples. The first step was $4 \frac{1}{2}$ minutes, followed by placing the specimens at an angle on the stage in the chamber and repeating the coating. Samples were treated for totals of $61 / 2$ and 9 minutes to decrease incidence of charging. Standard procedures were used to set up the JEOL JSM-T330A; essential parts of this set up include the correct filament saturation and proper stigmation. Images were obtained using Semaphore Scan Software. Images were scanned at 1024 X 1024, with a dwell time of 196 for high image resolution. Images were saved as greyscale TIFF files.

\section{Image pro plus vertical Analysis (cross-section)}

The initial step of analysis cross sections was establishing a master software calibration using the (Spatial Calibration) tool. A master calibration was made using the $100 \mu \mathrm{m}$ of the $\mathrm{x} 200 \mu \mathrm{m}$ magnification for the cross section images. Prior to collecting measurements from the image, a verification measurement was taken of the scale bar of the each image. Cross-section images of chicken eggshells were taken to measure shell thickness using the length tool. Three measurements were made for each cross section area criterion (total shell and palisade layer thickness) and the average was obtained and statistically analyzed; eggshell total length or 
thickness (TT) for each specimen was measured as a distance from the exterior surface of shell (eroded cuticle site) to the interior surface (melted membrane fibres abutting or calcium cap layer conjunction with eliminated membranes). While, Palisade layer (PL) or (cones) length (effective thickness) was measured as a distance from the free outside plane of shell till starting point appearing calcium columns cleavage or split.

\section{Statistical analysis}

Data were subjected to a one-way analysis of variance with breed effect using the General Linear Models (GLM) procedure of SAS User's Guide, 2001.

\section{RESULTS AND DISCUSSION}

\section{Egg weight and dimension}

Weights and dimensions of eggs for Dumyati and Muscovy eggs are presented in Table (1). It could be noticed the Muscovy ducks produced significantly heavier egg weight when compared to Dumyati breed. The genetic differences between breeds for egg weight was reported by Carter and Jones (1970); Potts et al. (1974); Arafa et al. (1982). The Muscovy eggs recorded the widest egg width compared with Dumyati breed. The last results reflected on the shape index, whereas the egg Muscovy ducks recorded the higher egg shape index than Dumyati eggs. The genetic difference between breeds for shape index was reported by Potts et al. (1974); Arafa et al. (1982). The eggshell surface play an important role during the incubation period specially in general breeds which comparatively thin and high porosity shells. The area surface of egg affected the porosity of shell and hence the degree of evaporation from the shell. The present result speculated that the egg shell area of Muscovy eggs were significantly higher than that of Dumyati breed.

Table 1. Egg weights and dimensions of Dumyati and Muscovy ducks

\begin{tabular}{lccc}
\hline \multirow{2}{*}{ Trait } & \multicolumn{2}{c}{ Breed } & Level of Sig. \\
\cline { 2 - 3 } Egg weight, g & Dumyati & Muscovy & \\
Egg shape index, \% & $61.42 \pm 1.06$ & $69.55 \pm 1.52$ & 0.0001 \\
Eggshell area, cm ${ }^{2}$ & $72.59 \pm 0.96$ & $74.86 \pm 0.10$ & 0.02 \\
\hline
\end{tabular}

$\mathrm{N}=50$ eggs/breed

\section{Eggshell traits}

The function of the eggshell is to protect the contents of the egg from mechanical impacts and microbacterial invasions and to control the exchange of water and gases through the pores during the extrauterine development of the chick embryo (Nys et $a l ., 1999)$. In the food market, the eggshell functions as a packaging material and its good quality is crucial to consumer selection and safety. So, great care is needed to preserve it intact. Eggshell traits of Dumyati and Muscovy eggs are summarized in Table (2). Thickness of the shell is significantly influenced by breed (Pandey et al., 1986). The eggshell weight and percentage were significantly affected by breed, whereas the Muscovy ducks were significantly higher in eggshell weight, percentage and also thickness compared to Dumyati breed. With respect to breaking strength, it could be noticed that the Muscovy eggs were significantly higher breaking strength compared to Dumyati breed. 
Table 2. Eggshell traits for Dumyati and Muscovy duck eggs

\begin{tabular}{lccc}
\hline & \multicolumn{2}{c}{ Breed } & Level of Sig. \\
\cline { 2 - 3 } Trait & Dumyati & Muscovy & \\
\hline Eggshell, g & $5.69 \pm 0.17$ & $7.08 \pm 0.21$ & 0.0001 \\
Eggshell, \% & $9.26 \pm 0.21$ & $10.17 \pm 0.17$ & 0.0001 \\
Eggshell thickness, mm & $0.417 \pm 0.01$ & $0.473 \pm 0.01$ & 0.0001 \\
Breaking strength, kg/cm2 & $5.04 \pm 0.09$ & $5.56 \pm 0.13$ & 0.01 \\
\hline
\end{tabular}

$\mathrm{N}=50$ eggs/breed

\section{Internal egg quality}

Egg content traits of Dumyati and Muscovy eggs are summarized in Table (3). Albumen characteristics quality has been reported as quantitative genetic traits. Eisen and Bohren (1963) found that possible to list desirable characteristics of numerical expression of albumen quality. The present results showed that there were significant differences between breeds for albumen and yolk weight, whereas the Muscovy eggs were significantly heavier albumen and yolk weight compared to Dumyati breed. Inversely, there was no significant difference between breeds for albumen and yolk percentage. The proportion of albumen had a high heritability and is controlled by additive multiple factors (Scheinberg et al., 1953). The Muscovy ducks had significantly higher albumen height compared to Dumyati eggs. Eggs produced from both Muscovy and Dumyati ducks recorded almost similar Haugh Units. The yolk index of Muscovy eggs was higher but not significantly than that of Dumyati ones.

Table 3. Egg content traits of Dumyati and Muscovy duck eggs

\begin{tabular}{lccc}
\hline \multirow{2}{*}{ Trait } & \multicolumn{2}{c}{ Breed } & \multirow{2}{*}{ Level of Sig. } \\
\cline { 2 - 3 } Albumen, g & Dumyati & Muscovy & \\
Albumen, \% & $35.21 \pm 1.19$ & $39.48 \pm 0.95$ & 0.01 \\
Albumen height, mm & $57.17 \pm 1.23$ & $56.80 \pm 0.79$ & NS \\
Haugh Unit & $7.97 \pm 0.15$ & $8.35 \pm 0.14$ & 0.02 \\
Yolk, g & $89.52 \pm 0.77$ & $89.59 \pm 0.93$ & NS \\
Yolk, \% & $20.52 \pm 0.66$ & $22.99 \pm 0.76$ & 0.02 \\
Yolk height, mm & $33.57 \pm 1.26$ & $33.02 \pm 0.77$ & NS \\
Yolk diameter, mm & $20.63 \pm 0.34$ & $20.96 \pm 0.28$ & NS \\
Yolk index & $43.70 \pm 0.88$ & $47.26 \pm 0.51$ & 0.0001 \\
\hline No & $21.28 \pm 0.60$ & $22.62 \pm 0.43$ & NS \\
\hline
\end{tabular}

$\mathrm{N}=50$ eggs/breed

\section{Eggshell Ultrastructure \\ Eggshell ultrastructure (transverse sectional)}

The vertical section of eggshell scanned with electron microscope showed distinguished two layers (mammillary and palisade layer) of eggshell (Fig. 1 and 2). Muscovy breed produced eggs with highly density mammillary pointed caps with irregular shape. Inversely, the Dumyati breed had low density rounded and conformity mammillary caps eggshells. The last results indicated that the Muscovy breed had better eggshell ultrastructure than Dumyati one. Simons (1971) suggested that the numbers, size of mammillae per unit area and the thickness may play a significant role in this scheme of eggshell. King and Robinson (1972) found that in weak thin shells the mammillae were in irregular shape, porous and frequently fragmented. Van Toledo et al. (1982) proposed that a low mammillary density was 
generally a feature of stronger shells. The more mammillae per unit area greater the chance of stress concentrations forming at the points of fusion between adjacent cones (Bain, 1990). Roberts and Brackpool (1994) documented that the mammillae of weak shells were irregularly shaped, often fragmented, pointed in shape and not firmly attached to the outer shell membrane fibers. Strong eggshells had a lower density of mammillary knobs than those with weak shells. Density of mammillary cones may contribute to shell strength, although, density cannot be considered without references to the size of cones (Chowdhury and Davis, 1995). El-Delbshany et al. (2007) reported that good eggshell quality should have mammillary bodies that are even in size and distribution and rounded so that there can be maximizing attachment to the fibers of the outer membrane.

Table (4) clarified the total thickness of eggshell under electron microscope $(\mu \mathrm{m})$ and thickness of both layers (mammillary and palisade) in $\mu \mathrm{m}$ and its percentage to the total thickness $(\%)$ for Dumyati and Muscovy eggs at 24 wks old. Data revealed that Muscovy eggs owned the thicker eggshell compared to Dumyati ones with highly significant difference. Regarding palisade thickness (effective thickness) and percentage, Muscovy breed recorded higher value with highly significant difference in compared to Dumyati ones. Radwan (2007) stated that the proportion of palisade layer could be playing an important role in shell stiffness. As for second distinct layer of eggshell, mammillary layer thickness and percentage values were differed between breeds. There was significant difference between the two breeds for cap thickness. The Dumyati eggshell had significantly higher mammillary percentage compared to Muscovy ones. The mammillary layer of the domestic hen's egg shell is embedded partly in the outer shell membrane and is responsible for the attachment of the major part of the shell to the keratin-like shell membranes which enclose to the albumen. The occurrence in active secreting isthmus tissues of only neutral mucins together with the observation that eggs isolated from the isthmus contained crystalline mammillary cores shows that the mammillary cores are formed in the isthmus and also that shell formation is nucleated in the isthmus (Robinson and King, 1970). Robinson and King (1963) suggested that anhydrase enzyme is localized at the mammillary cores. Bain (1991) and Ruiz and Lunam (2000) reported that the palisade layer provides the stiffness characteristics of the shell and thereby shell strength. Thus, a reduction in its relative thickness could compromise shell strength leading to a higher incidence of breakage. Radwan (2007) found that the proportion of mammillary and palisade layers independent on shell thickness.

Table 4. Absolute and Relative thickness of the individual eggshell layers in eggs of Dumyati and Muscovy ducks

\begin{tabular}{lccc}
\hline \multirow{2}{*}{ Trait } & \multicolumn{2}{c}{ Breed } & Level of \\
\cline { 2 - 3 } Sig. \\
\hline Total thickness, $\mu \mathrm{m}$ & $278.44 \pm 10.33$ & $362.54 \pm 11.86$ & 0.001 \\
Palisade thickness, $\mu \mathrm{m}$ & $212.67 \pm 9.85$ & $286.64 \pm 10.12$ & 0.001 \\
Cap thickness, $\mu \mathrm{m}$ & $65.78 \pm 8.70$ & $75.90 \pm 1.45$ & 0.001 \\
Palisade, \% & $76.73 \pm 8.21$ & $79.09 \pm 9.42$ & 0.01 \\
Cap, \% & $23.27 \pm 4.25$ & $20.91 \pm 3.67$ & 0.05 \\
\hline
\end{tabular}

$\mathrm{N}=8$ eggshell/ breed 
Bain (1990) documented that the strength of an eggshell is not simply determined by thickness, but is dependent on a balanced shell architecture to which the different components of the shell all contribute. The stiffness characteristics of the eggshell are resident in the palisade layer (effective thickness); the mammillary layer per se does not influence this property (Bain, 1990). Bain (1992) found that the effective thickness (the distance from the point of fusion of the palisade columns to the outer edge of the cuticle) measured by scanning electron microscopy was more effect shell strength and the name of true shell not shell thickness using a digital micrometer. Bain et al. (2006) stated that the term of effective thickness (palisade layer) must conserve as a tool for selection programs in both broiler breeders and parent stock of layers.

\section{Eggshell ultrastructure (horizontal sectional)}

Solomon (1991) and Bain (2005) described twelve structural variations in the mammillary layer of weak and poor quality eggshells. Watt (1985) found that there were a high proportion of structural abnormalities in the cone layer of those eggs which were cracked or broken. Information from Table (5) clarified the various constructions present in the interior surface of eggshell after removing shell membranes viz it being in mammillary layer which can affecting on eggshell stiffness. Respecting confluence trait, data showed that the Muscovy eggs owned shells with higher values of confluence. Muscovy eggs showed good mammillary cap confluence and extensive confluent caps, that proved good conjunction with shell membranes, and consequently increases eggshell, compared to Dumyati one. Solomon (1999) found good shell ultrastructural beneficial high confluence reflects good attachment with membranes and caps (Fig.2). Concerning fusion trait, significant differences observed between Dumyati and Muscovy eggshells regarding fusion (early or late). Where, Muscovy eggshell have superior values than Dumyati ones. Fig.3 clarified the superiority for Muscovy eggshell with early fusion aspect compared to Dumyati ones that produced late fusion shell eggs. Thus where fusion is late, crack propagation through the shell wall, and thereafter outwards from the load point will occur more rapidly. Bain (1990) stated that the decline in fracture toughness can be explained in terms of an increase in late fusion of adjacent mammillary columns (and the types of abnormality which accompany this).

There were no significant differences for cuffing material between breeds. With respect to alignment trait, the present results showed that alignment comes out to be significantly differed between Muscovy and Dumyati breeds, where Dumyati breed had the higher alignment value than Muscovy one. This clearly presented in Fig. (5), where Dumyati breed owned extensive alignment figures among columns compared to Muscovy one, that produced eggs have low mammillary alignment.

Significant differences were found between Dumyati and Muscovy duck eggshells as for type B's structure. Fig. 6 showed extensive type B's in Dumyati eggshell, that's reduced the eggshell quality as a harmful figure disjoined adjacent columns adhesion. Nascimento et al. (1992) stated that the aberrant crystal forms of type B's provide no meaningful contribution to the palisade layer and like the poor cap modifications, which do not offer any anchorage point. In accordance to depression and erosion traits, both breeds were significantly differed in these traits. Fig. 7 declared detected erosion in mammillary layer of poor structured eggshell for Dumyati breed. Erosion trait is the most severe types of structural fault found in the eggshell. It is thought that erosion creates areas of weakness within the eggshell. 
There were significant differences between the two breeds concerning Cubics and Aragonite shapes. Concerning caps layer, it appears to be significantly different between both duck breeds, where Dumyati owned higher values of caps compared to Muscovy ones. Type A's not significantly differed between both breeds. Figure (8) showed the Type A's of basal mammillary cones in Dumyati breed eggshells. Type A's appears to be associated only with the basal cap crystals of the mammillae as indicated by little or no evidence of contact with the membrane fibers (Bain, 1990). Changed membranes for Dumyati and Muscovy ducks not significantly differed. Watt and Solomon (1985) reported that the changed membranes were presented in the shells of relatively old hens (80-90 wks old). The lack of establishment between shell and membrane fibers at this point obviously creates the ideal portal crack and bacterial penetration.

In conclusion, this study demonstrates the superiority for egg quality, mechanical properties and Ultrastructural eggshell traits of Muscovy eggs at the beginning of laying period than Dumyati eggs.

Table 5. Ultrastructural variants of eggshell mammillae for Dumyati and Muscovy breeds

\begin{tabular}{lccc}
\hline & \multicolumn{2}{c}{ Breed } & Level of signif. \\
\cline { 2 - 3 } Trait & Dumyati & Muscovy & \\
\hline Confluence & $2.67 \pm 0.11$ & $3.00 \pm 0.12$ & 0.01 \\
Fusion & $3.67 \pm 0.08$ & $2.33 \pm 0.09$ & 0.01 \\
Cuffing & $1.36 \pm 0.001$ & $1.33 \pm 0.002$ & $\mathrm{NS}$ \\
Alignment & $4.00 \pm 0.13$ & $1.67 \pm 0.10$ & 0.01 \\
Type B's & $3.33 \pm 0.10$ & $0.83 \pm 0.11$ & 0.001 \\
Depression & $2.33 \pm 0.12$ & $1.33 \pm 0.14$ & 0.001 \\
Erosion & $2.67 \pm 0.14$ & $1.67 \pm 0.12$ & 0.001 \\
Cubic & $1.00 \pm 0.002$ & $1.00 \pm 0.02$ & $\mathrm{NS}$ \\
Aragonite & $1.00 \pm 0.003$ & $1.00 \pm 0.01$ & $\mathrm{NS}$ \\
Caps & $4.00 \pm 0.14$ & $3.82 \pm 0.10$ & $\mathrm{NS}$ \\
Type A's & $2.33 \pm 0.10$ & $2.40 \pm 0.003$ & $\mathrm{NS}$ \\
Changed membrane & $1.00 \pm 0.02$ & $1.00 \pm 0.004$ & $\mathrm{NS}$ \\
Total score & $29.36 \pm 2.10$ & $21.38 \pm 1.88$ & 0.001 \\
\hline
\end{tabular}

$\mathrm{N}=8$ eggshell/ breed

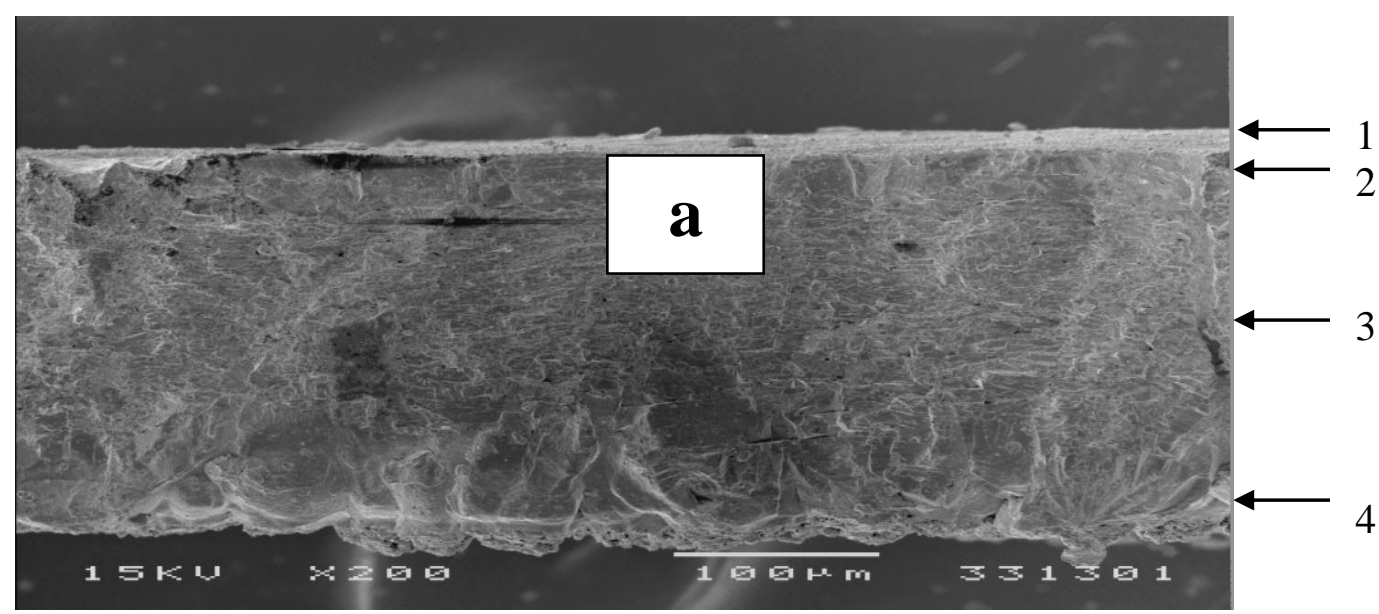




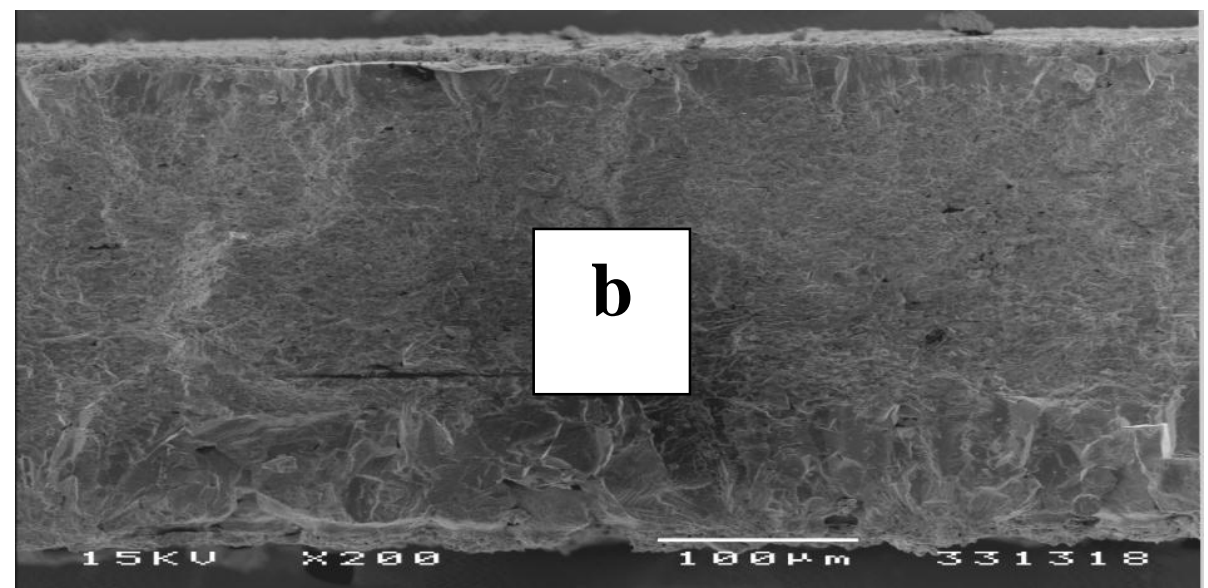

Figure 1. Transverse sections of eggshell from various duck breeds by SEM: (a) Dumyati and (b) Muscovy. 1. Cuticle, 2. Vertical crystals layer, 3. Palisade layer, 4. Caps layer Bar $=100 \mu \mathrm{m}$

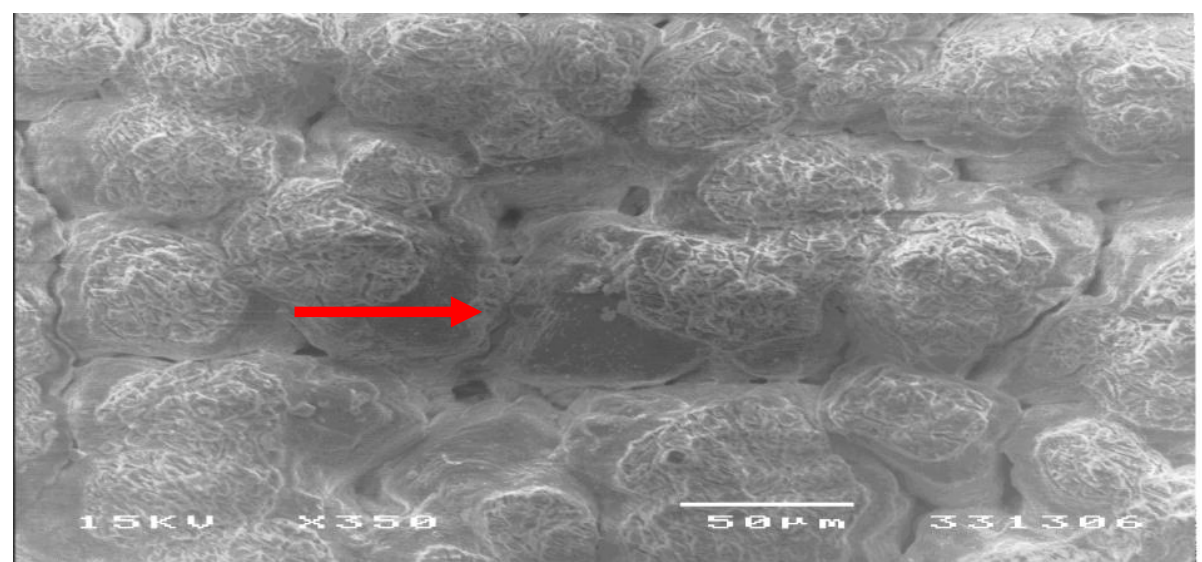

Figure 2. Good mammillary caps and good confluence in Muscovy eggs

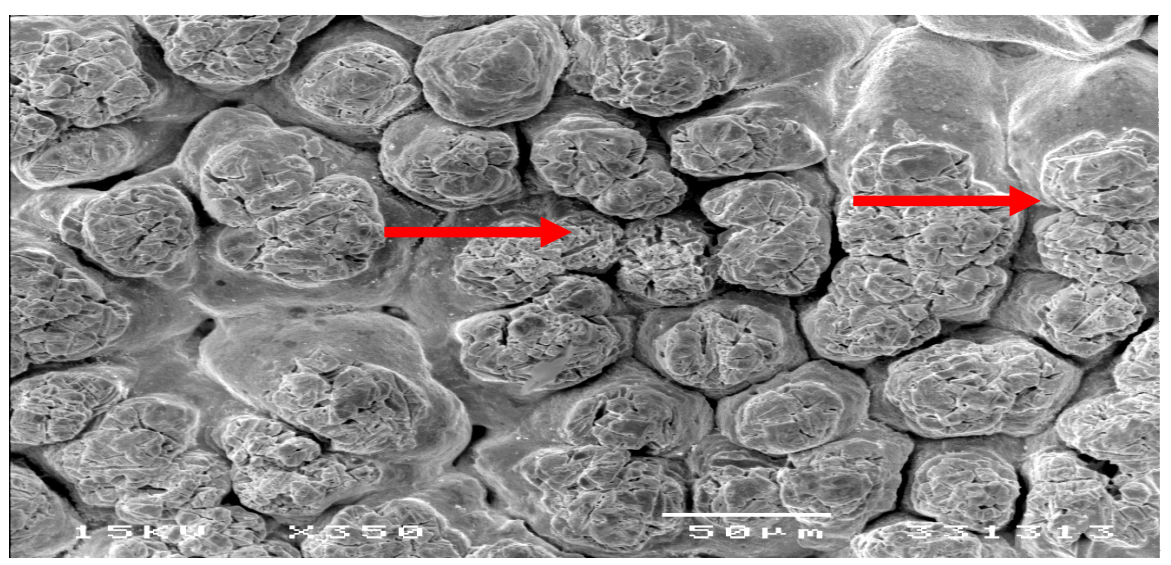

Figure 3 Early fusion and good confluence of mammillae in Muscovy eggs 


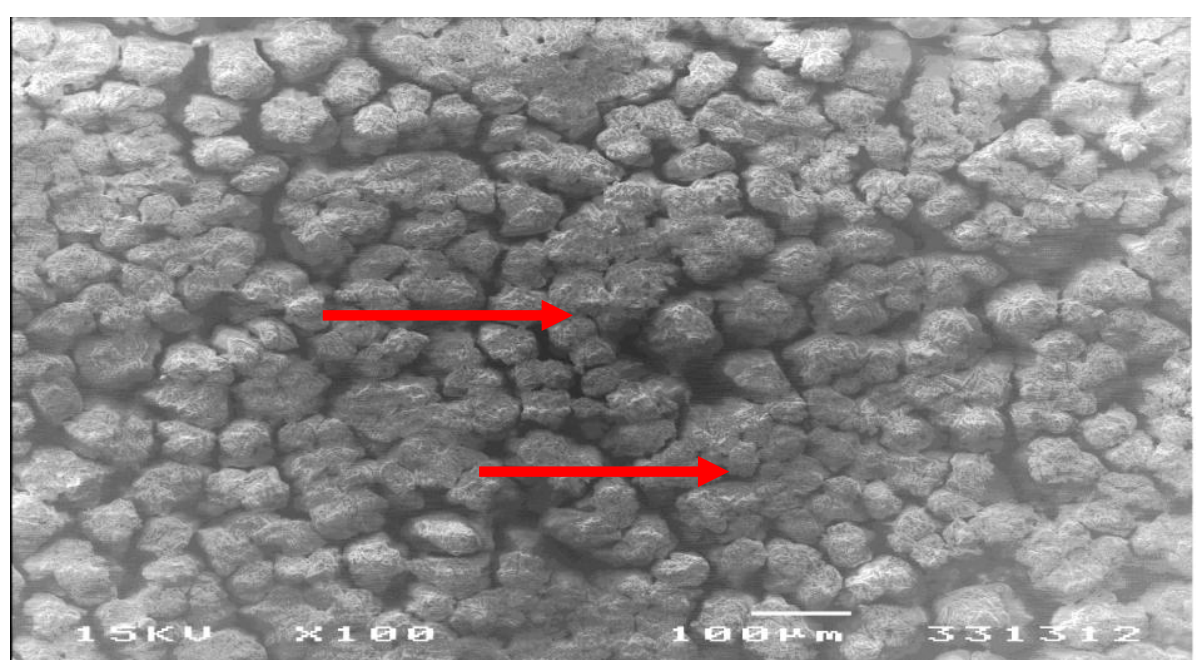

Figure 4. Alignment in Dumyati eggs

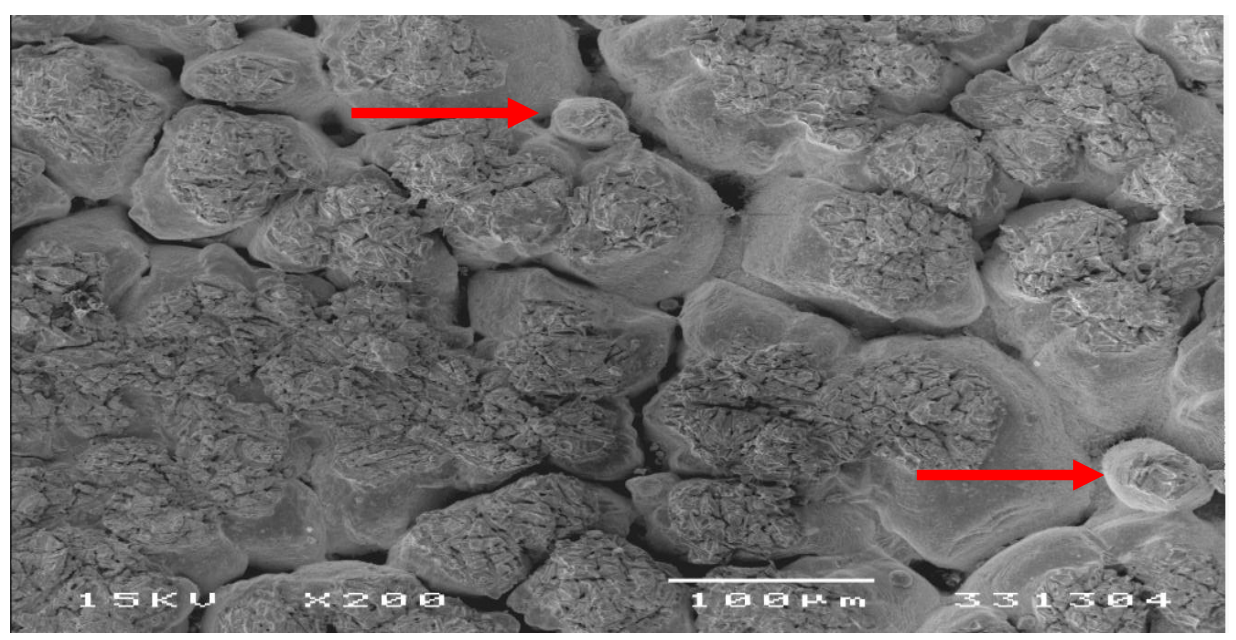

Figure 6. Type B's in Dumyati eggs 


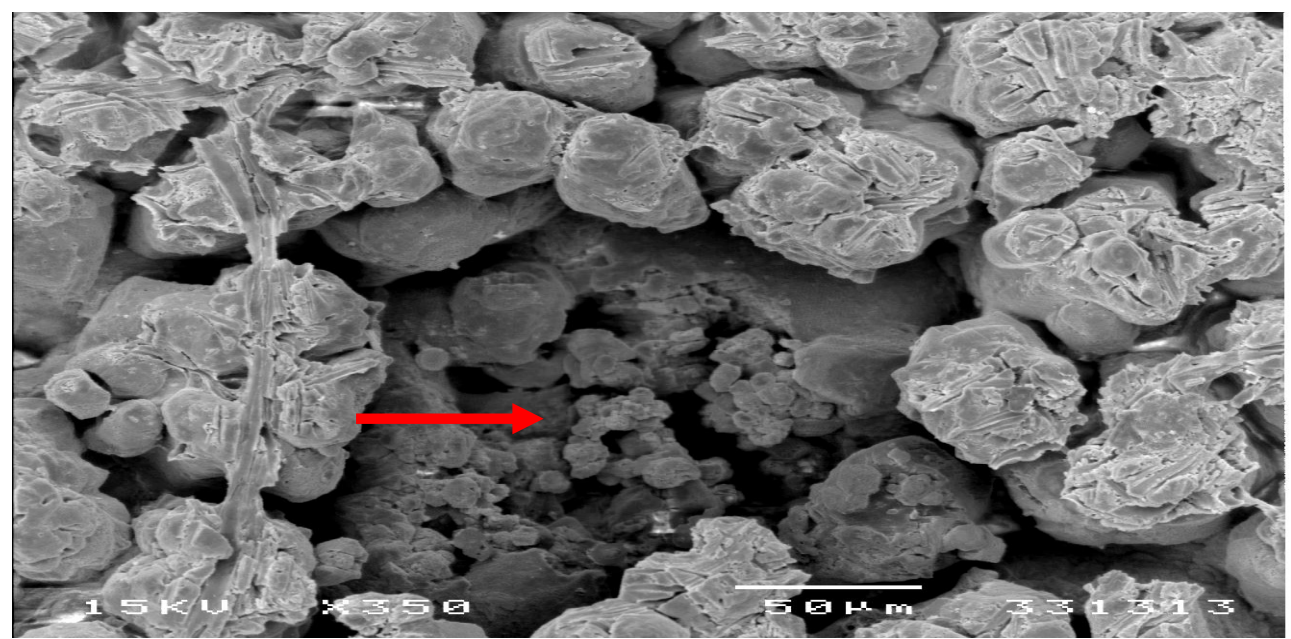

Figure 7. Erosion in mammillae and poorly structured area of Dumyati eggshell

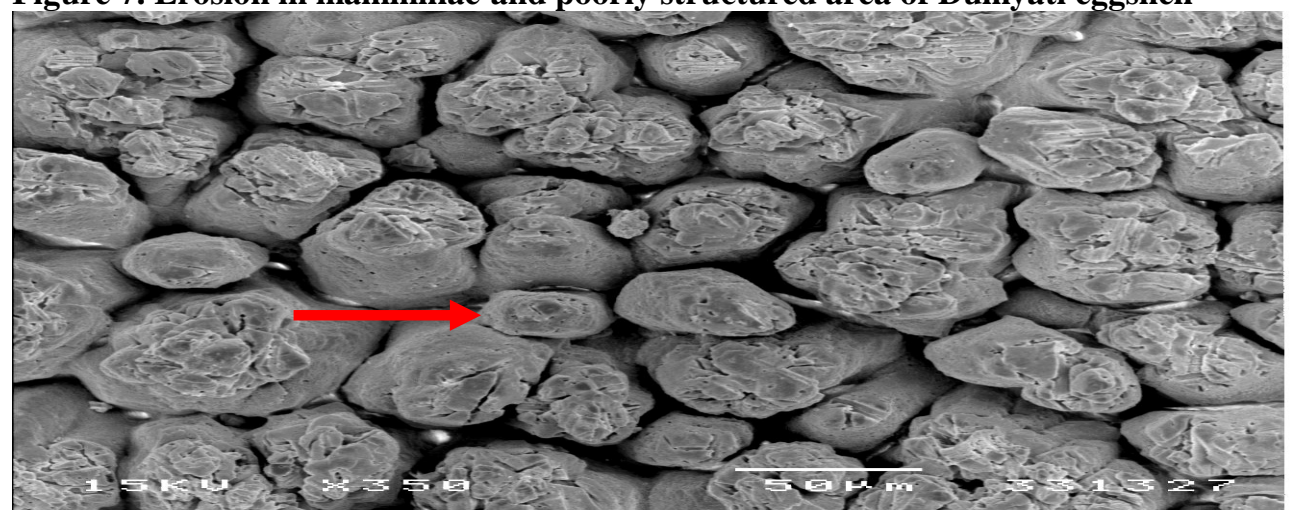

Figure 8. Type A's of basal mammillary caps and late fusion in Dumyati eggs

\section{REFERENCES}

Ahmed, A.M.H., A.B. Rodriguez-Navarro, M.L. Vidal, J. Gautron, J.M. Garcia-ruiz and Y. Nys, 2005. Changes in eggshell mechanical properties, crystallographic texture and in matrix proteins included by moult in hens. Br. Poult. Sci. 46: 268279.

Altan, O., I. Oguz and Y. Akbas (1998). Effects of selection for high body weight and age of hen on egg characteristics in Japanese quail (coturnix coturnix japonica). Turk. J. Vet. Anim. Sci., 22: 467-473.

Arafa, A. S., R. H. Harms, R. D. Miles, R. B. Christmas and J. H. Choi (1982). Quality characteristics of eggs from different strains of hens as related to time of Oviposition. Poult. Sci., 61: 842-47.

Bain, M. M. (1991). A reinterpretation of eggshell strength, in Solomon, S. E. Egg and eggshell quality, P. 131-144, Wolf Pub. Ltd., London.

Bain, M.M. (1990). Eggshell strength: a mechanical ultrastructural evaluation. Ph. D. Thesis, Faculty of Veterinary Medicine, University of Glasgow. 
Bain, M.M. (1992). Eggshell strength a relationship between the mechanism of failure and ultrastructure organization of the mammillary layer. Br. Poult. Sci., 33: 303-319.

Bain, M.M. (2005). Recent advances in the assessment of eggshell quality and their future application. World's Poult .Sci., 61:268-277.

Bain, M.M.; N. Macleod; A. Thomson; and J.W. Hancock (2006). Microcracks in eggs. Poult. Sci., 85:2001-2008.

Carter, T. C. and R. M. Jones, (1970). The hen's egg shell shape parameters and their interrelations. Br. Poult. Sci., 11: 179-87.

Chowdhury, S. D. and R. H. Davis (1995). Influence of dietary osteolathyrogens on the ultrastructure of shell and membranes of eggs from laying hens. Br. Poult. Sci., 36: 575-583.

Eisen, E. J. and B. B. Bohren (1963). Some problems in the evaluation of egg albumen quality. Poult. Sci., 42: 74-83.

Eisen, E. J., B. B. Bohren and H. A. McKean (1962). The Haugh units as a measure of albumen quality. Poult. Sci., 41: 1461-1468.

El-Dlebshany, A.E., S.A. El-Safty, M. Bahie El-Deen and M.M. Fathi (2007). Ultrastructural evaluation of eggshell in Japanese quail genetically selected for higher egg production. Proceedings of 4th World's Poult. Conf. Sharm ElSheikh, Egypt. pp. 208-217.

Farooq M., Mian M. A., Murad A., Durrani F. R., Asghar, A. and Muqarrab A. K. (2001) egg traits of Fayumi birds under subtropical conditions. Sarhad Journal of Agriculture, 7(2): 141-145.

Fathi, M.M. and E.A. El-Sahar (1996). Determining the strength of eggshell by using an appropriate apparatus and an equation to calculate egg surface depending on its dimensions. Egypt. Poult. Sci., 16: 285-303.

Hamilton, R. M. G. (1982). Methods and factors that affect the measurement of egg shell quality. Poult. Sci., 61:2022-2039.

Khurshid, A., M. Farooq, F. R. Durrani, K. Sarbiland and N. Chand (2003) Predecting egg weight, shell weight, shell thickness and hatching chick weight of Japanese quails using various egg traits as regessors. Int. J. Poult. Sci., 2: 164167.

King, N. R. and D. S. Robinson (1972). The use of the scanning electron microscope for comparing the structure of weak and strong shells. J. of Microscopy, 95 (3): 437-443.

Nascimento, V. P., S. Cranstoun and S. E. Solomon (1992). Relationship between shell structure and movement of Salmonella Entritidis across the eggshell wall. Br. Poult. Sci., 33: 37-48.

Nys, Y., J. Gautron, J.M. Garcia-Ruiz and M.T. Hincke (2004). Avian eggshell mineralization: Biochemical and functional characterization of matrix proteins. Comptes Rendus Palevol, 3:549-562.

Nys, Y., J. L. Hincke, J.M. Arias, J.M. Garcia- Ruiz and S.E. Solomon (1999). Avian eggshell mineralization. Poultry and Avian Biology Reviews 10:143-166.

Paganelli, C. V., Olszowka A. and Ar A. (1974). The avian egg: surface area, volume and density. Condor, 76:319-325

Pandey, N. K., C. M. Mahapatra, S. S. Verma and D. C. Johari (1986). Effect of strain on physical egg quality characteristics in white leghon chickens. Ind. J. Poult. Sci., 21: 304-307. 
Potts, P. L., K. W. Washburn and K. K. Hale (1974). Shell evaluation of white and brown egg strains by deformation, breaking strength, shell thickness and specific gravity. 1- Relationship to egg characteristics. Poult. Sci., 53: 1123-1128.

Radwan, L. M. (2007). Comparative study on ultrastructural measurements of eggshell quality in some local breeds of chicken using modern techniques. M. Sc. Thesis, Fac. of Agric., Ain Shams Uni., Egypt.

Roberts, J. R. and C. E. Brackpool (1994). The ultrastructure of avian eggshell. Poult. Sci. Rev., 5: 245-274.

Robinson, D.S. and N.R. King (1963). Carbonic anhydrase and formation of the hens egg shell. Nature, 199: 497-498.

Robinson, D.S. and N.R. King (1970). The structure of the organic mammillary cores and cuticle of the hen egg shell. Br. Poult. Sci., 36: 345-352.

Rodriguez-Navarro, A., O. Kalin, Y. Nys and J.M. Garcia-Ruiz (2002). Influence of the microstructure on the shell strength of eggs laid by hens of different ages. Br. Poult. Sci., 43: 395-403.

Ruiz, J. and C.A. Lunam (2000). Ultrastructural analysis of the eggshell: contribution of the individual calcified layers and the cuticle to hatchability and egg viability in broiler breeds. Poult. Sci., 41: 584-592.

SAS Institute (2001). SAS/STAT User's Guide:Statistics. Ver.8.2,SAS Institute Inc.,Cary, NC

Sauveur, B. (1988). Reproduction des volailles et production d'œufs (Paris, INRA Edition).

Scheinberg, S. L., H. Ward and A. W. Nordskog (1953). Breeding for egg quality. 1. Heritability and repeatability of egg weight and its components. Poult. Sci., 32: 504-510.

Simons, P.C.M. (1971). Ultrastructure of the hens eggshell and its physiological interpretation. Ph.D. Thesis Spelderholt, Beekbergen, Netherlands.

Solomon, S.E. (1985). Eggshell quality: A structural evaluation. Poult. Sci., 24:5865.

Solomon, S.E. (1991). Egg and eggshell quality, Wolfe Publishing Ltd. London.

Solomon, S.E. (1999). An egg, ist ein ei, es un huevo, est un oeuf. Br. Poult. Sci., 40:05-11.

Stadelman, W. J. (1977). Quality identification of shell egg. Egg Sci. and Technol., P. 36, 2nd Ed., Pub. Comp. Inc. Connecticut.

Van Toledo, B.; A.H. Parsons and G.F. Coombs (1982). Role of ultrastructure in determining eggshell strength. Poult. Sci., 61: 569-578.

Watt, J.M. and S.E. Solomon (1985). The incidence of mammillary layer abnormalities in the eggshells of commercial breeding flocks, J. Anat.,140, 542.

Williams, K. C. (1992). Some factors affecting albumen quality with particular reference to Haugh unit score. World's Poult. Sci., 48: 5-16. 


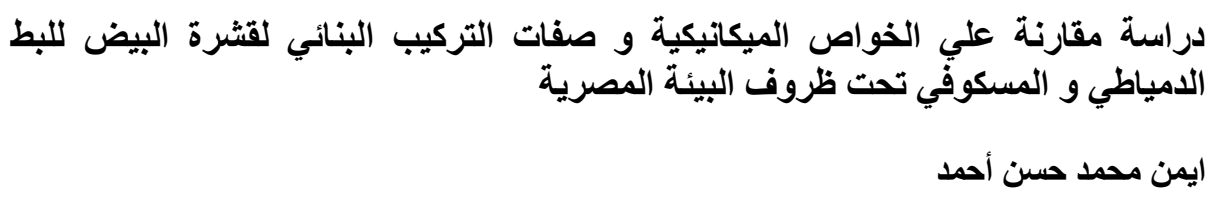

قسم إنتاج الدواجن، كلية الزراعة، جامعة عين شمس، القاهرة، مصر

تم تقييم جودة البيض و الخواص الميكانيكية و صفات التركيب البنائي للقنشرة في البط الدمياطي و

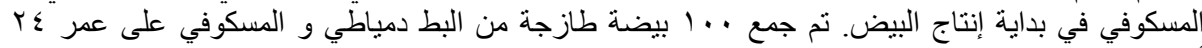

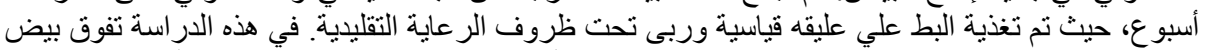

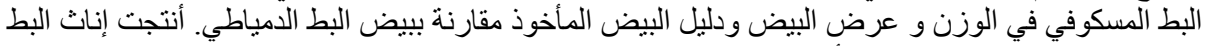

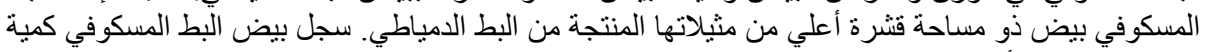

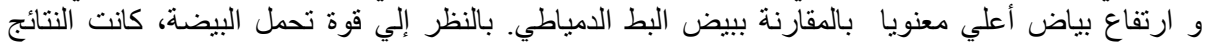

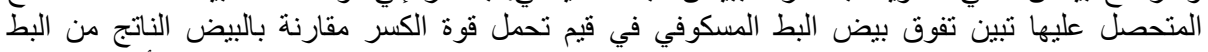

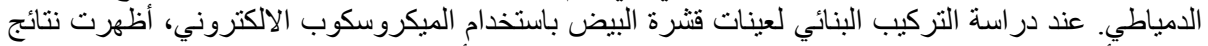

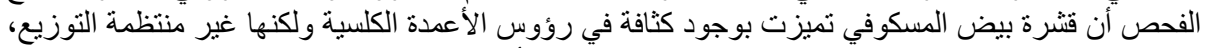

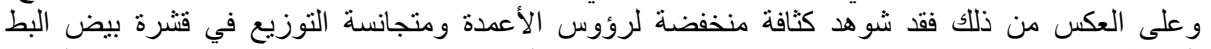

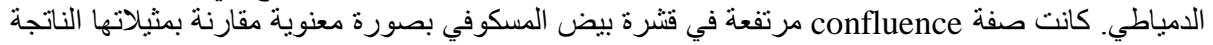

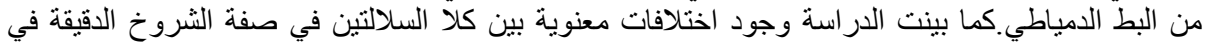

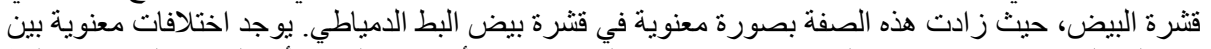

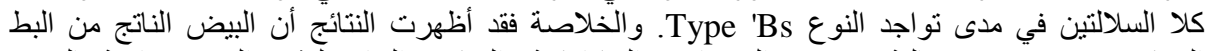

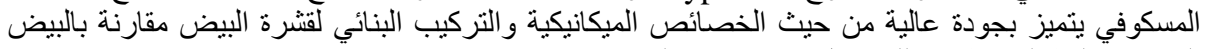
الناتج من البط الدمياطي وذلك خلال فترة الإنتاج المبكرة. 